\title{
Comparisons of Dipstick Test, Urine Protein-to-Creatine Ratio, and Total Protein Measurement for the Diagnosis of Preeclampsia
}

\author{
Katarzyna Stefańska ${ }^{1, *,+} \mathbb{D}$, Maciej Zieliński ${ }^{2,+}{ }^{+}$, Dorota Zamkowska ${ }^{1}$ (D), Przemysław Adamski ${ }^{1}$, \\ Joanna Jassem-Bobowicz ${ }^{3}$, Karolina Piekarska ${ }^{2}$, Martyna Jankowiak ${ }^{2}$, Katarzyna Leszczyńska ${ }^{1}$, \\ Renata Świątkowska-Stodulska ${ }^{4}$, Krzysztof Preis ${ }^{1}$, Piotr Trzonkowski ${ }^{2}$ and \\ Natalia Marek-Trzonkowska ${ }^{5,6}$ \\ 1 Department of Obstetrics, Medical University of Gdańsk, 80-214 Gdańsk, Poland; \\ dorotaaw@gmail.com (D.Z.); padamski@gumed.edu.pl (P.A.); kasiabor1@wp.pl (K.L.); kpreis@wp.pl (K.P.) \\ 2 Department of Medical Immunology, Medical University of Gdańsk, 80-214 Gdańsk, Poland; \\ mzielinski@gumed.edu.pl (M.Z.); karolinapiekarska18@gmail.com (K.P.); martyna830@gumed.edu.pl (M.J.); \\ ptrzon@gumed.edu.pl (P.T.) \\ 3 Department of Neonatology, Medical University of Gdańsk, 80-214 Gdańsk, Poland; jmjassem@gmail.com \\ 4 Department of Endocrinology and Internal Medicine, Medical University of Gdańsk, 80-214 Gdańsk, Poland; \\ rensto@gumed.edu.pl \\ 5 Cancer Immunology Group, International Centre for Cancer Vaccine Science, University of Gdansk, \\ 80-214 Gdańsk, Poland; natalia.marek@gumed.edu.pl \\ 6 Laboratory of Immunoregulation and Cellular Therapies, Department of Family Medicine, \\ Medical University of Gdańsk, 80-214 Gdańsk, Poland \\ * Correspondence: kciach@wp.pl; Tel.: +48-502-115-942 \\ + These authors equally contributed to this study.
}

Received: 11 May 2020; Accepted: 10 June 2020; Published: 12 June 2020

check for updates

\begin{abstract}
Preeclampsia affects 2-5\% of pregnant women and is one of the leading causes of maternal and perinatal morbidity and mortality. We aimed to extensively evaluate proteinuria in women with preeclampsia and to determine the analytical sensitivity and specificity of and the cutoff values for urine protein-to-creatinine ratio (UPCR) and total protein in $24 \mathrm{~h}$ urine samples. This study included 88 women. We used the urine dipstick test, UPCR, and total protein measurement in a $24 \mathrm{~h}$ urine sample. The patients were divided in gestational hypertension $(\mathrm{GH}, n=44)$ and preeclampsia (PE, $n=44)$ groups. In the GH group, $25 \%(11 / 44)$ of the patients presented incidentally positive results. UPCR and total protein in $24 \mathrm{~h}$ urine specimens were increased in the GH group compared to the PE group. Receiver operating characteristic analysis showed a UPCR cutoff of $30 \mathrm{mg} / \mathrm{mmol}$ as significant for preeclampsia, while the sensitivity and specificity were $89 \%(95 \% \mathrm{CI}, 75-97)$ and $100 \%$ (95\% CI, 87-100), respectively. In the $24 \mathrm{~h}$ urine protein test, sensitivity and specificity were $80 \%$ (95\% CI, 61-92) and 100\% (95\% CI, 88-100), respectively, for the cutoff value of $0.26 \mathrm{~g} / 24 \mathrm{~h}$. In comparison to the other commonly used tests here considered, UPCR determination is a reliable, relatively faster, and equally accurate method for the quantitation of proteinuria, correlates well with $24 \mathrm{~h}$ urine protein estimations, and could be used as an alternative to the $24 \mathrm{~h}$ proteinuria test for the diagnosis of preeclampsia.
\end{abstract}

Keywords: preeclampsia; gestational hypertension; pregnancy; urine protein-to-creatinine ratio; proteinuria; $24 \mathrm{~h}$ urine sample 


\section{Introduction}

Preeclampsia (PE) is a multisystem disorder of pregnancy and is defined as the onset of hypertension accompanied by significant proteinuria after 20 weeks of gestation [1]. PE typically affects $2-5 \%$ of pregnant women and is one of the leading causes of maternal and perinatal morbidity and mortality, especially when the condition is of early onset [1,2]. Globally, 76,000 women and 500,000 babies die each year from this disorder [1,3].

According to the International Society for the Study of Hypertension in Pregnancy (ISSHP), preeclampsia, transient gestational hypertension, and gestational hypertension $(\mathrm{GH})$ are characterized by the new onset of hypertension (systolic blood pressure $\geq 140 \mathrm{mmHg}$ or diastolic blood pressure $\geq 90 \mathrm{mmHg}$ ) at or after 20 weeks of gestation [4]. Normal blood pressure either in pre-pregnancy or in early pregnancy is important before its pregnancy-related decrease [4-6].

Gestational hypertension is hypertension arising de novo after 20 weeks of gestation in the absence of proteinuria and without biochemical or hematological abnormalities. It is usually not accompanied by fetal growth restriction. Outcomes in pregnancies complicated by gestational hypertension are normally good, but about a quarter of women with gestational hypertension (particularly those who present it before 34 weeks of gestation) will progress to preeclampsia and have poorer outcomes [4].

Preeclampsia is a multisystem disorder that manifests after the 20th week of gestation. It is characterized by hypertension and at least one of the following conditions: (1) proteinuria, (2) other maternal organ dysfunction, including acute kidney injury (AKI) (creatinine $\geq 90 \mu \mathrm{mol} / \mathrm{L} ; 1 \mathrm{mg} / \mathrm{dL}$ ), liver involvement (elevated transaminases, e.g., aspartate aminotransferase (AST) or alanine aminotransferase $(\mathrm{ALT})>40 \mathrm{IU} / \mathrm{L}$ ) with or without right upper quadrant or epigastric abdominal pain), neurological complications (examples include eclampsia, altered mental status, blindness, stroke, clonus, severe headaches, persistent visual scotomata), hematological complications (thrombocytopeniaplatelet count below 150,000/ $\mu \mathrm{L}$, disseminated intravascular coagulation (DIC), (3) uteroplacental dysfunction (such as fetal growth restriction (FGR), abnormal umbilical artery Doppler wave form, or stillbirth) [4].

Proteinuria is not mandatory for a diagnosis of preeclampsia but is present in about $75 \%$ of cases. Rather, PE is diagnosed by the presence of de novo hypertension after 20 weeks of gestation accompanied by proteinuria and/or evidence of maternal acute kidney injury, liver dysfunction, neurological features, hemolysis or thrombocytopenia, and/or fetal growth restriction. Preeclampsia may develop or be recognized for the first time intrapartum or early post-partum in some cases [4].

Moreover, $\mathrm{PE}$ is characterized by reduced renal perfusion and damage to glomerular basement membrane resulting in leakage of proteins in the urine. Irrespective of the cause of hypertension, the quantification of proteinuria in pregnancy is vital not only for making a diagnosis but also for predicting maternal and fetal outcomes. Normally, pregnant women excrete minimal amounts of proteins in the urine (up to $150 \mathrm{mg} /$ day) because of renal changes that occur during pregnancy; however, proteinuria $>300 \mathrm{mg} /$ day is considered abnormal for pregnant women.

Several methods for proteinuria evaluation are available in daily practice: (1) dipstick, (2) $24 \mathrm{~h}$ urine protein test, and (3) urine protein-to-creatinine ratio (UPCR). In the first method, urine test stripes are used. A standard test strip comprises up to 10 chemical pads that serve for the analysis of different parameters (e.g., proteins, $\mathrm{pH}$, erythrocytes, leukocytes, nitrites, glucose, ketones). The test can be read within 60-120 s after dipping the stripe in a urine sample. The chemical pads change color after being immersed in the sample, and the results are interpreted by comparison of the pad color with the colors presented in the dipstick analysis guide. A $24 \mathrm{~h}$ urine protein test requires a $24 \mathrm{~h}$ collection of a urine sample. Then, one aliquot is taken from the total volume of the $24 \mathrm{~h}$ urine sample and tested. The UPCR, like the dipstick test is based on the analysis of a random urine sample, but like the $24 \mathrm{~h}$ urine protein test, it provides quantitative results. The UPCR has been validated for use as an estimator of $24 \mathrm{~h}$ urine protein levels from one random urine sample by analysis of the protein-to-creatinine ratio.

In clinical practice, proteinuria is assessed initially by automated dipstick urinalysis when possible; if this is not available, a careful visual dipstick urinalysis will suffice. If positive $\left(\geq^{\prime} 1+^{\prime}, 30 \mathrm{mg} / \mathrm{dL}\right)$, 
the UPCR should be determined. A UPCR $\geq 30 \mathrm{mg} / \mathrm{mmol}(0.3 \mathrm{mg} / \mathrm{mg})$ is abnormal. A negative dipstick test can usually be accepted, and further UPCR testing is not required at that time. Proteinuria is not required for a diagnosis of pre-eclampsia. Massive proteinuria $(>5 \mathrm{~g} / 24 \mathrm{~h})$ is associated with more severe neonatal outcomes [4].

Generally, the estimation of $24 \mathrm{~h}$ urine proteins has been considered the gold standard for quantitation of proteinuria [7]. However, the collection of a $24 \mathrm{~h}$ urine sample is inconvenient for the patient and prone to pre-analytical errors, thereby leading to inaccurate results or variations in the application of the assay [8]. Thus, the urine dipstick test or the UPCR is widely used to confirm proteinuria [6]. Recently, an appropriate cutoff value for the UPCR was set; however, the pros and cons of proteinuria testing are still debated $[9,10]$. Apparently, each analytical approach has some limitations, such as inaccuracy due to daily variations of protein secretion, falsely positive/negative results, and ease of sample testing [11-13].

In this study, we aimed to extensively evaluate proteinuria in women suspected of having GH or PE by comparing three available methods for protein testing: urine dipstick test, UPCR, and total protein in $24 \mathrm{~h}$ urine samples. We tested the analytical sensitivity and specificity and determined the cutoff values for UPCR in single mid-stream urine samples and total protein in $24 \mathrm{~h}$ urine samples. Moreover, we assessed biochemical parameters, such as serum creatinine, transaminases, and platelets, and evaluated their usefulness as additional markers of PE.

\section{Materials and Methods}

\subsection{Study Design}

This study included all patients with GH or PE (88 pregnant women) who were hospitalized between April 2015 and July 2017 at the Department of Obstetrics, Medical University of Gdansk, Poland. The patients were between 27 and 42 weeks of gestation with a singleton pregnancy with symptoms of GH or PE but without co-morbidities. Women with chronic secondary/essential hypertension, immunological diseases like Hashimoto's disease, diabetes mellitus, pre-existing renal disease, intrauterine fetal death, multiple gestations, gestational diabetes and bacteriuria, multiple pregnancy, assisted reproductive technology in pregnancy, and premature rupture of membranes were excluded from the study. This study was approved by the Bioethics Committee at the Medical University of Gdansk (no. NKBBN/454/2014) and was conducted according to the principles of the Declaration of Helsinki. All participants provided a written informed consent to participate in the study.

\subsection{Patients}

Based on clinical and laboratory evaluations, according to the ISSHP classification, the patients were divided into two groups: GH group $(n=44)$ and PE group $(n=44)$. The study flow diagram is shown in Figure 1, and the baseline characteristics of the study population are provided in Table 1.

GH was defined as systolic blood pressure $\geq 140 \mathrm{~mm} \mathrm{Hg}$ and diastolic blood pressure $\geq 90 \mathrm{~mm}$ $\mathrm{Hg}$ in a previously normotensive pregnant woman after 20 weeks of gestation without proteinuria or a sign of end-organ dysfunction. PE was diagnosed in patients with a high blood pressure ( $24 \mathrm{~h}$ respiratory rate records) and new-onset proteinuria, i.e., when resting blood pressure was $\geq 140 / 90 \mathrm{mmHg}$ on two occasions that were at least $4 \mathrm{~h}$ apart, and significant proteinuria was detected in urine samples. In the absence of proteinuria, PE was diagnosed in women with hypertension in association with thrombocytopenia (platelet count $<150,000 / \mu \mathrm{L}$ ), impaired liver function (increased blood levels of liver aminotransferases to twice the normal concentration), new development of renal insufficiency (elevated serum creatinine $>1.02 \mathrm{mg} / \mathrm{dL}$ ), pulmonary edema, new-onset cerebral or visual disturbances, or uteroplacental dysfunction, including FGR. FGR was diagnosed as fetal abdominal circumference/estimated fetal weight $<10$ th percentile combined with pulsatility index in the umbilical artery $>95$ th percentile, or pulsatility index in the uterine artery $>95$ th percentile, or abdominal 
circumference/estimated fetal weight $<3$ rd percentile, or absent end-diastolic flow in the umbilical artery [14].

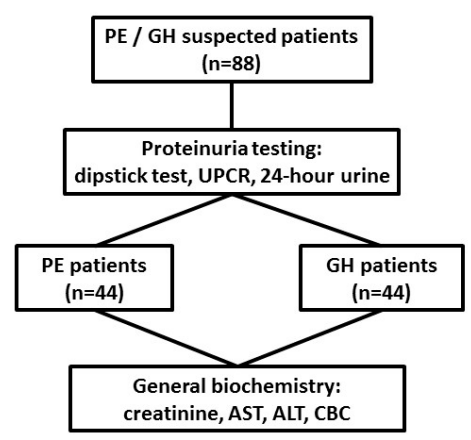

Figure 1. Study flow diagram. Patients were classified into two groups based on clinical features and proteinuria assessment: preeclampsia (PE) group $(n=44)$ or gestational hypertension $(\mathrm{GH})$ group $(n=44)$, and general biochemistry tests were performed. UPCR: urine protein-to-creatinine ratio, AST-aspartate aminotransferase: ALT-alanine aminotransferase: CBC-complete blood count.

Table 1. Patient characteristics.

\begin{tabular}{cccc}
\hline Patients Status & PE & GH & $\boldsymbol{p}^{\boldsymbol{a}}$ \\
\hline Age (years, mean $\pm \mathrm{nD})$ & $28 \pm 4.05$ & $30 \pm 4.60$ & 0.124 \\
Period of gestation & 35 & 39 & $2.469 \times 10^{-6}$ \\
Body mass index $\left(\mathrm{kg} / \mathrm{m}^{2}\right)$ & 30 & 33 & $7.013 \times 10^{-8}$ \\
(median, min/max) & $(21 / 46)$ & $(26 / 42)$ & \\
Parity & & & $\mathrm{NT}$ \\
0 & 36 & 34 & $\mathrm{NT}$ \\
1 & 7 & 7 & $\mathrm{NT}$ \\
\hline$>$
\end{tabular}

${ }^{a} \chi^{2}$ test of association or Mann-Whitney U-test comparing PE vs. GH; NT-not tested.

\subsection{Methods}

Proteinuria was assessed with the urine dipstick test, UPCR, and total protein in $24 \mathrm{~h}$ urine samples in each patient during hospitalization. The urine dipstick test was performed twice, and a positive result was considered significant. Subsequently, creatinine, AST, ALT, and complete blood count (CBC) were evaluated. Serum and urine biochemical parameters were assayed with Architect analytical system (Abbott) and CBC with Sysmex analytical system (Sysmex). The urine dipstick test was performed with the Iris urinalysis system (Beckman Coulter).

\subsection{Statistical Analysis}

All analyses were performed using Statistica 11.0 (Statsoft). Between-group differences were determined using nonparametric tests. Significance was set at $p<0.05$. A receiver operating characteristic (ROC) analysis was performed to verify the diagnostic usefulness of the evaluated markers, and data are presented with 95\% confidence interval (CI). Data are expressed as medians with interquartile range. Heat map and principal component analyses were performed in ClustVis, based on the Euclidean distance between clusters [15].

\section{Results}

\subsection{Proteinuria Testing}

Three different methods were used for proteinuria evaluation: urine dipstick test, UPCR, and total protein in a $24 \mathrm{~h}$ urine sample. In 9\% (4/44) of the patients in the PE group, the urine dipstick test was 
falsely negative in the first test, while the second test revealed a positive result. In the GH group, $25 \%$ (11/44) of the patients had falsely positive results in the urine dipstick test; UPCR and $24 \mathrm{~h}$ urine test did not confirm the dipstick test results, but all three tests were performed. Moreover, UPCR (median 10683.00 vs. $16.41[\mathrm{mg} / \mathrm{mmol}] ; p=5.21 \times 10^{-10}$; Mann-Whitney $\mathrm{U}$ test) and total protein in a $24 \mathrm{~h}$ urine specimen (median 0.98 vs. $0.16[\mathrm{~g} / 24 \mathrm{~h}] ; p=4.38 \times 10^{-6}$; Mann-Whitney U test) were higher in the PE group. Each positive UPCR result corresponded to a significant total protein value in the $24 \mathrm{~h}$ urine specimen. The UPCR cutoff value of $30 \mathrm{mg} / \mathrm{mmol}$ was validated as significant for PE, based on the ROC analysis. While the area under curve was 0.96 ( $p<0.0001 ; 95 \% \mathrm{CI}, 0.921-1.004)$, the sensitivity and specificity were $89 \%$ (95\% CI, 75-97) and 100\% (95\% CI, 87-100), respectively. In the $24 \mathrm{~h}$ urine protein test, the area under the curve, sensitivity, and specificity were 0.94 ( $p<0.0001 ; 95 \% \mathrm{CI}, 0.881-1.008), 80 \%$ (95\% CI, 61-92), and 100\% (95\% CI, 88-100), respectively, for the cutoff value of $0.26 \mathrm{~g} / 24 \mathrm{~h}$ (Figure 2).

\section{A}

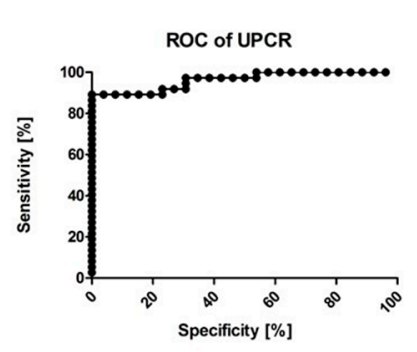

c

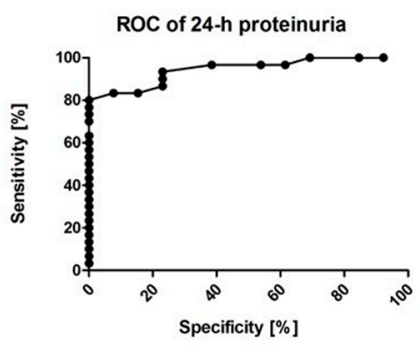

B

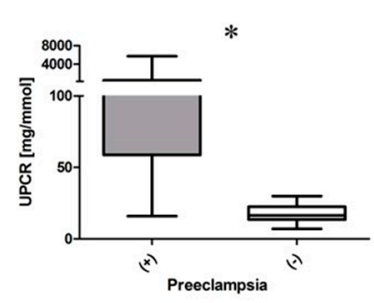

D

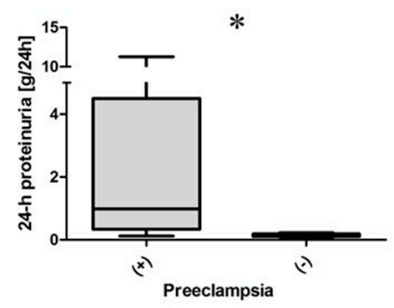

Figure 2. Proteinuria testing. Protein loss was assessed by determining the UPCR and performing the $24 \mathrm{~h}$ urine test. The UPCR cutoff of $30 \mathrm{mg} / \mathrm{mmol}$ was adequate for the diagnosis of preeclampsia (A). The UPCR values increased in the PE group (B). For the cutoff value of $0.26 \mathrm{~g} / 24 \mathrm{~h}$, the total protein level in $24 \mathrm{~h}$ urine samples was adequate for the diagnosis of PE (C). Total protein was increased in the PE group (D); ${ }^{*} p<0.05$.

\subsection{General Biochemistry Testing}

The CBC results showed that patients with PE and GH did not differ in whole-blood platelet (PLT) count (median 213.00 vs. $220.00\left[10^{9} / \mathrm{L}\right] ; p=0.612$; Mann-Whitney U test) and hematocrit (HCT) (median 44.90 vs. 35.20 [\%]; $p=0.08$; Mann-Whitney U test); however, the GH group had a higher hemoglobin ( $\mathrm{Hgb}$ ) concentration (median 12.60 vs. $11.90[\mathrm{~g} / \mathrm{dL}] ; p=0.012$; Mann-Whitney $\mathrm{U}$ test). Moreover, serum AST (median 21.50 vs. $16.00[\mathrm{U} / \mathrm{L}] ; p=4.87 \times 10^{-5}$ ) and ALT (median 16.50 vs. $11.00[\mathrm{U} / \mathrm{L}] ; p=1.42 \times 10^{-3}$; Mann-Whitney $\mathrm{U}$ test) concentrations increased in the PE group compared to those in the GH group, but not serum creatinine (median 0.69 vs. $0.68[\mathrm{mg} / \mathrm{dL}] ; p=0.269$; Mann-Whitney U test).

ROC analysis was performed to determine the parameters' sensitivity and specificity and to validate them as markers of PE. The area under curve, sensitivity, and specificity were $0.536(p=0.559$; 95\% CI, 0.413-0.659), 57\% (95\% CI, 41-72), and 45\% (95\% CI, 30-61), respectively, for PLT; 0.630 $(p=0.035 ; 95 \%$ CI, 0.512-0.748), 61\% (95\% CI, 46-76), and 66\% (95\% CI, 48-78), respectively, for HCT; and 0.657 ( $p=0.011 ; 95 \% \mathrm{CI}, 0.542-0.772), 61 \%(95 \% \mathrm{CI}, 46-76)$, and $59 \%$ (95\% CI, 43-74), respectively, for $\mathrm{Hgb}$. The area under curve, sensitivity, and specificity were $0.753(p=0.0001 ; 95 \% \mathrm{CI}, 0.646-0.860), 70 \%$ 
(95\% CI, 53-84), and 66\% (95\% CI, 49-80), respectively, for ALT; 0.700 ( $p=0.002 ; 95 \%$ CI, $0.585-0.814)$, 73\% (95\% CI, 56-86), and 61\% (95\% CI, 45-76), respectively, for AST; and 0.569 ( $p=0.270 ; 95 \%$ CI, $0.447-0.692), 60 \%$ (95\% CI, 43-75), and 48\% (95\% CI, 32-63), respectively, for creatinine (Figure 3).

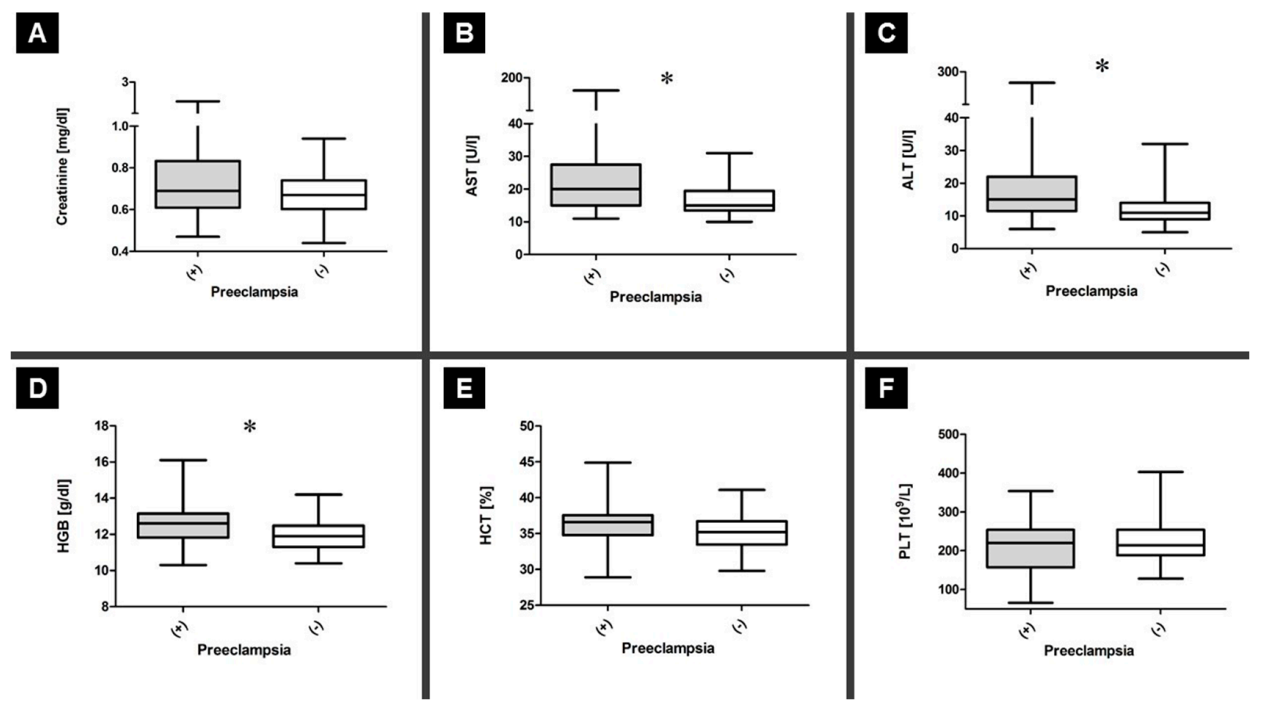

Figure 3. General biochemistry testing. The levels of creatinine (A), AST (B), ALT (C), hemoglobin $(\mathrm{Hgb0})(\mathbf{D})$, hematocrit (HCT) (E), and platelet count (PLT) (F) were compared between the PE and GH groups. Significant differences in AST, ALT, and PLT (F) were compared between the PE and the GH groups. Significant differences in AST, ALT, and platelet count were noted and indicated with "*"; * $p<0.05$.

Neither principal component analysis nor heat maps with clustering revealed differences in the collectively analyzed data between patients with PE and GH (Figure 4).

A

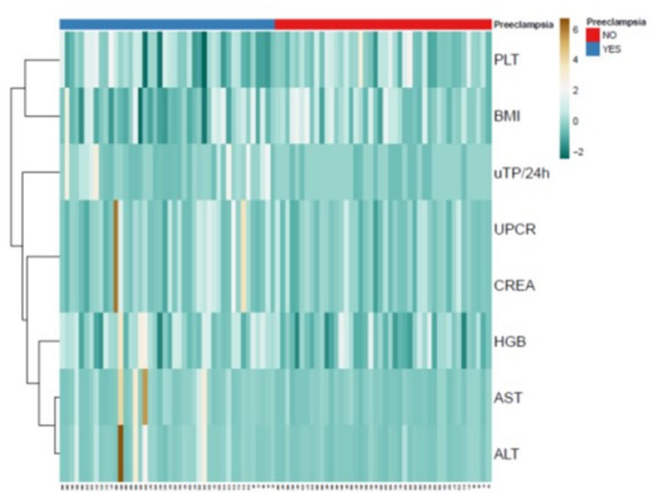

B

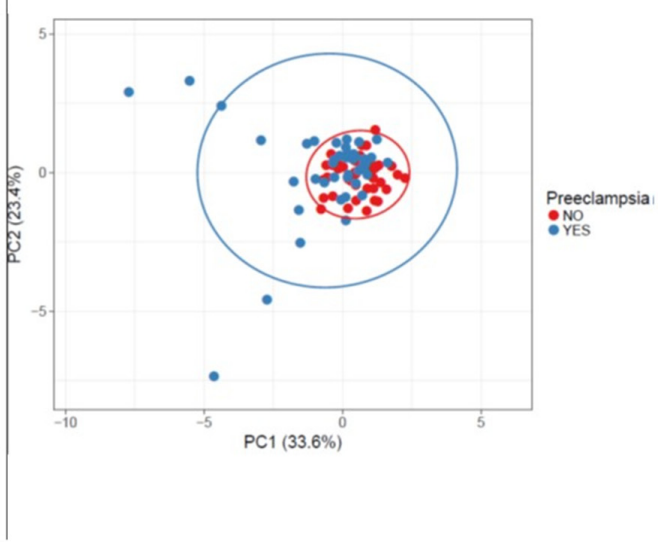

Figure 4. Heat maps and principal component analysis (PCA) analysis. Heat maps based on the Euclidean distance between clusters for patients with PE and GH (A). PCA graph for the PE and GH groups (B). The $X$ and $Y$ axes show principal component 1 and principal component 2, which explain $33.6 \%$ and $23.4 \%$ of the total variance, respectively.

\section{Discussion}

In this study, we assessed the utilization of proteinuria and biochemical parameters as markers of PE.

The urine dipstick test is a semi-quantitative assay, while the UPCR and total protein in the $24 \mathrm{~h}$ urine test allow quantitative determinations. The urine dipstick test is a screening assay, which could 
detect positive cases (true disease). However, our data showed that $9 \%$ of patients were misdiagnosed as not having proteinuria using a single urine dipstick test, and a second sample testing was required. By contrast, the UPCR and total protein in a $24 \mathrm{~h}$ urine sample could fully distinguish patients with PE and $\mathrm{GH}$, and a second test was not needed. Moreover, urine dipstick test results may vary depending on the maternal hydration status. Thus, even trace proteinuria may be reported as significant if the mother is dehydrated, and in contrast, proteinuria may be missed if the mother is overhydrated. In addition, the test readout could be altered depending on the test features (limit of detection and limit of quantification), alkalinity of the urine, and presence of infections. This is important, as proteinuria must be confirmed or excluded in pregnant women presenting with hypertension in order to diagnose PE.

In our cohort, both UPCR and total protein in the $24 \mathrm{~h}$ urine test were validated as adequate for PE diagnosis. Both their sensitivity and their specificity were good enough to appropriately identify patients with PE or GH. However, while the $24 \mathrm{~h}$ urine test is considered the gold standard for proteinuria testing, the test itself is cumbersome, time-consuming, and prone to pre-analytical errors, which could in turn results in lack of compliance by and inconvenience to patients. Also, resting in the supine position during hospitalization may result in urine stagnation in the renal system, and the amount of collected urine may not reflect the actual $24 \mathrm{~h}$ volume. Hence, UPCR is a potentially useful marker of PE. As previously shown, UPCR was not affected by variations in urine concentration and the amount of urine excreted in $24 \mathrm{~h}$ [16]. Our study demonstrates that UPCR is as valuable as the $24 \mathrm{~h}$ urine test in patients with preeclampsia, and a UPCR cutoff of $30 \mathrm{mg} / \mathrm{mmol}$ coincides with proteinuria in the corresponding $24 \mathrm{~h}$ urine sample.

Creatinine was not adequate for PE diagnosis; its levels were comparable in patients with PE and with GH. Such a finding is apparently surprising, as one could suspect that protein loss due to altered renal filtration coexists with increased serum creatinine. Nevertheless, stable creatinine levels reflect adaptive renal capacities, and increased creatinine is more specific to kidney injury, while irreversible damage causes glomerulonephritis.

Although AST, ALT, and PLT levels increased in the PE compared to the GH group, none of these values is useful for PE diagnosis based on the ROC analysis. Similar to creatinine, this finding may be because of early diagnoses in our cohort and lack of complications due to prolonged hypertension and proteinuria or signs of end-organ dysfunction. Collectively, the early diagnosis of protein loss due to hypertension prevented the subsequent development of full-blown preeclampsia with clinical symptoms and increased markers of tissue damage.

The significant correlation between UPCR and proteinuria in $24 \mathrm{~h}$ urine samples is a noteworthy finding of our study. While the latter represents the gold standard for the diagnosis of proteinuria, it delays diagnosis by $24 \mathrm{~h}$, is not well tolerated by the patients, and cannot be performed in an emergency room setting. When identifying markers of PE, not only sensitivity and specificity should be considered but also turnaround time from sampling to results, which may in turn lead to timelier decision-making, likely reduce patients' anxiety, shorten the length of hospital stay, thereby minimizing the associated cost, and help "target" women with a real pathology for treatment.

In practice, the $24 \mathrm{~h}$ urine protein measurement could mostly be replaced by a spot test determining urine protein/creatinine ratio, with a value $\geq 30 \mathrm{mg}$ per $\mathrm{mmol}(=0.26 \mathrm{mg} / \mathrm{mg}$, usually 'rounded' to $0.3 \mathrm{mg} / \mathrm{mg}$ ) representing significant proteinuria. This would eliminate the inherent difficulties in undertaking $24 \mathrm{~h}$ urine collections and speed up the process of decision-making [4]. At present, there are insufficient data to recommend using the urinary albumin/creatinine ratio, but this may change when more research becomes available, such as the results of the DAPPA (Diagnostic Accuracy in Preeclampsia using Proteinuria Assessment, RCTN82607486) clinical trial [4,17-19].

The determination of the protein/creatinine ratio would be a valuable tool for the early diagnosis of preeclampsia if its accuracy is acceptable. It could prevent unnecessary hospitalizations and testing and allow earlier diagnoses [20]. Several studies have evaluated the usefulness of the protein-to-creatinine ratio as a screening tool for the determination of proteinuria in subjects with suspected preeclampsia [17]. Sanchez's study, as well as three systematic reviews with meta-analyses, have shown that the 
protein-to-creatinine ratio correlates well with the results of a subsequent 24 hour urine test and is useful for the diagnosis of significant proteinuria [17,18,20,21].

Although the $24 \mathrm{~h}$ urine collection is still accepted as the gold standard for the diagnosis of proteinuria during pregnancy, some authorities have suggested that the protein-to-creatinine ratio should be employed as the preferred method of quantifying proteinuria. It is recommended to use the $24 \mathrm{~h}$ urine test for subjects with an abnormal protein-to-creatinine ratio [17]. In addition, Waugh et al. concluded that the collection of a $24 \mathrm{~h}$ urine sample has comparable value to that of a spot urine sample to quantify proteinuria in women with hypertension in pregnancy [22]. Therefore, these results from Waugh's study do not support the recommendation of a $24 \mathrm{~h}$ urine sample collection for hypertensive pregnant women. Once the UPCR is confirmed to be $>30 \mathrm{mg} / \mathrm{mmol}$, no further proteinuria measurements are required during hypertensive pregnancies. A randomly determined urine protein-to-creatinine ratio provides useful evidence to rule out the presence of significant proteinuria in patients at risk for preeclampsia [16,22].

\section{Conclusions}

Although the $24 \mathrm{~h}$ urine test for total protein remains the gold standard for proteinuria evaluation, it has several limitations. The dipstick test has insufficient specificity and sensitivity; nevertheless, because of its simplicity and cost, it may still be used as a primary screening method but is not suitable for the quantitation of proteinuria. In comparison, the UPCR is a reliable, relatively faster, and equally accurate method for the detection and quantitation of proteinuria; it correlates well with the $24 \mathrm{~h}$ urine protein estimation and, thus, could be used as an alternative to $24 \mathrm{~h}$ urine testing for patients suspected of preeclampsia. Furthermore, the UPCR test can be performed in emergency room settings and is more clinically useful for the assessment of proteinuria in pregnant women with hypertension.

Author Contributions: Conceptualization: K.S., N.M.-T. and P.T.; methodology: M.Z., software: M.Z.; validation: K.S. and M.Z.; formal analysis: K.S. and N.M.-T. and M.Z.; investigation: J.J.-B.; resources: P.A., D.Z., M.J., K.L., R.Ś.-S., K.P. (Karolina Piekarska), K.P. (Krzysztof Preis) and J.J.-B.; data curation: K.P. (Karolina Piekarska), D.Z., M.J. and K.P. (Krzysztof Preis); writing-original draft preparation: K.S., M.Z., D.Z. and N.M.-T.; writing-review and editing: K.S., M.Z. and D.Z.; visualization: M.Z.; supervision: K.P. (Krzysztof Preis), P.T., N.M.-T. and K.S.; project administration: K.S., M.Z. and N.M.-T.; funding acquisition: K.S., N.M.-T. and P.T. All authors have read and agreed to the published version of the manuscript.

Funding: This study was supported by funds from the Polish National Science Center on the basis of Decision no. 2014/15/B/NZ5/03499. NMT was supported by ICCVS project, carried out within the IRAP program of the Foundation for Polish Science, co-financed by the European Union under the European Regional Development Fund.

Conflicts of Interest: The authors declare no conflict of interest.

\section{References}

1. Poon, L.C.; Shennan, A.; Hyett, J.A.; Kapur, A.; Hadar, E.; Divakar, H.; McAuliffe, F.; da Silva Costa, F.; von Dadelszen, P.; McIntyre, H.D.; et al. The International Federation of Gynecology and Obstetrics (FIGO) initiative on pre-eclampsia: A pragmatic guide for first-trimester screening and prevention. Int. J. Gynaecol. Obstet. 2019, 145, 1-33. [CrossRef]

2. Ronsmans, C.; Graham, W.J. Lancet Maternal Survival Series steering group. Maternal mortality: Who, when, where, and why. Lancet 2006, 368, 1189-1200. [CrossRef]

3. Kuklina, E.V.; Ayala, C.; Callaghan, W.M. Hypertensive disorders and severe obstetric morbidity in the United States. Obstet. Gynecol. 2009, 113, 1299-1306. [CrossRef] [PubMed]

4. Brown, M.A.; Magee, L.A.; Kenny, L.C.; Karumanchi, S.A.; McCarthy, F.P.; Saito, S.; Hall, D.R.; Warren, C.E.; Adoyi, G.; Ishaku, S. International Society for the Study of Hypertension in Pregnancy (ISSHP). Hypertensive Disorders of Pregnancy: ISSHP Classification, Diagnosis, and Management Recommendations for International Practice. Hypertension 2018, 72, 24-43. [CrossRef] [PubMed]

5. Magee, L.A.; Pels, A.; Helewa, M.; Rey, E.; von Dadelszen, P. Canadian Hypertensive Disorders of Pregnancy (HDP) Working Group. Diagnosis, evaluation, and management of the hypertensive disorders of pregnancy. Pregnancy Hypertens. 2014, 4, 105-145. [CrossRef] [PubMed] 
6. Lowe, S.A.; Bowyer, L.; Lust, K.; McMahon, L.P.; Morton, M.; North, R.A.; Paech, M.; Said, J.M. SOMANZ guidelines for the management of hypertensive disorders of pregnancy 2014. Aust. N. Z. J. Obstet. Gynecol. 2015, 55, e1-e29. [CrossRef]

7. Amin, S.V.; Illipilla, S.; Hebbar, S.; Rai, L.; Kumar, P.; Pai, M.V. Quantifying proteinuria in hypertensive disorders of pregnancy. Int. J. Hypertens. 2014, 2014, 1-10. [CrossRef]

8. Cheung, H.; Leung, K.; Choi, C. Diagnostic accuracy of spot urine protein-to-creatinine ratio for proteinuria and its association with adverse pregnancy outcomes in Chinese pregnant patients with pre-eclampsia. Hong Kong Med. J. 2016, 22, 249-255. [CrossRef]

9. Gangaram, R.; Naicker, M.; Moodley, J. Accuracy of the spot urinary microalbumin:creatinine ratio and visual dipsticks in hypertensive pregnant women. Eur. J. Obstet. Gynecol. Reprod. Biol. 2009, 144, 146-148. [CrossRef]

10. Waugh, J.J.; Clark, T.J.; Divakaran, T.G.; Khan, K.S.; Kilby, M.D. Accuracy of urinalysis dipstick techniques in predicting significant proteinuria in pregnancy. Obstet. Gynecol. 2004, 103, 769-777. [CrossRef]

11. Waugh, J.J.; Bell, S.C.; Kilby, M.D.; Blackwell, C.N.; Seed, P.; Shennan, A.H.; Halligan, A.W. Optimal bedside urinalysis for the detection of proteinuria in hypertensive pregnancy: A study of diagnostic accuracy. BJOG 2005, 112, 412-417. [CrossRef] [PubMed]

12. Côté, A.-M.; Firoz, T.; Mattman, A.; Lam, E.M.; von Dadelszen, P.; Magee, L.A. The 24-hour urine collection: Gold standard or historical practice? Am. J. Obstet. Gynecol. 2008, 199, 625.e1. [CrossRef] [PubMed]

13. Waugh, J.; Bell, S.C.; Kilby, M.D.; Lambert, P.; Shennan, A.; Halligan, A. Urine protein estimation in hypertensive pregnancy: Which thresholds and laboratory assay best predict clinical outcome? Hypertens. Pregnancy 2005, 24, 291-302. [CrossRef]

14. Gordijn, S.J.; Beune, I.M.; Thilaganathan, B.; Papageorghiou, A.; Baschat, A.A.; Baker, P.N.; Silver, R.M.; Wynia, K.; Ganzevoort, W. Consensus definition of fetal growth restriction: A Delphi procedure. Ultrasound Obstet. Gynecol. 2016, 48, 333-339. [CrossRef] [PubMed]

15. Metsalu, T.; Vilo, J. ClustVis: A web tool for visualizing clustering of multivariate data using principal component analysis and heatmap. Nucleic Acids Res. 2015, 43, W566-W570. [CrossRef] [PubMed]

16. Huang, Q.; Gao, Y.; Yu, Y.; Wang, W.; Wang, S.; Zhong, M. Urinary spot albumin:creatinine ratio for documenting proteinuria in women with preeclampsia. Rev. Obstet. Gynecol. 2012, 5, 9-15.

17. Sanchez-Ramos, L.; Gillen, G.; Zamora, J.; Stenyakina, A.; Kaunitz, A.M. The protein-to-creatinine ratio for the prediction of significant proteinuria in patients at risk for preeclampsia: A meta-analysis. Ann. Clin. Lab. Sci. 2013, 43, 211-220.

18. Côté, A.M.; Brown, M.A.; Lam, E.; von Dadelszen, P.; Firoz, T.; Liston, R.M.; Magee, L.A. Diagnostic accuracy of urinary spot protein:creatinine ratio for proteinuria in hypertensive pregnant women: Systematic review. BMJ 2008, 336, 1003-1006. [CrossRef]

19. Morris, R.K.; Riley, R.D.; Doug, M.; Deeks, J.J.; Kilby, M.D. Diagnostic accuracy of spot urinary protein and albumin to creatinine ratios for detection of significant proteinuria or adverse pregnancy outcome in patients with suspected pre-eclampsia: Systematic review and meta-analysis. BMJ 2012, 345, e4342. [CrossRef]

20. Papanna, R.; Mann, L.K.; Kouides, R.W.; Glantz, J.C. Protein/creatinine ratio in preeclampsia: A systematic review. Obstet. Gynecol. 2008, 112, 135-144. [CrossRef]

21. Price, C.P.; Newall, R.G.; Boyd, J.C. Use of protein: Creatinine ratio measurements on random urine samples for prediction of significant proteinuria: A systematic review. Clin. Chem. 2005, 51, 1577-1586. [CrossRef] [PubMed]

22. Waugh, J.; Hooper, R.; Lamb, E.; Robson, S.; Shennan, A.; Milne, F.; Price, C.; Thangaratinam, S.; Berdunov, V. Bingham Spot protein-creatinine ratio and spot albumin-creatinine ratio in the assessment of pre-eclampsia: A diagnostic accuracy study with decision-analytic model-based economic evaluation and acceptability analysis. Health Technol. Assess. 2017, 21, 1-90. [CrossRef] [PubMed]

(C) 2020 by the authors. Licensee MDPI, Basel, Switzerland. This article is an open access article distributed under the terms and conditions of the Creative Commons Attribution (CC BY) license (http://creativecommons.org/licenses/by/4.0/). 